\title{
The Effects of Absorptive Capacity and Decision Speed on Organizational Innovation: A Study of Organizational Structure as an Antecedent Variable
}

\author{
Shin-Tien Chen \\ Mingchi University of Technology \\ E-Mail: cst@mail.mcut.edu.tw \\ Bao-Guang Chang \\ Tamkang University \\ E-Mail: baog@mail.tku.edu.tw
}

\begin{abstract}
Following the dimensions of organizational structure and organizational innovation, this paper aims to discuss how organizational structure affects organizational absorptive capacity and decision speed, and subsequently influences organizational innovation. Based on the sample of 260 enterprises with 1282 valid questionnaires, the empirical method, using the Structural Equations Model showed the following. (1) The higher the degree of organizational formalization, the stronger the absorptive capacity of the organization, and then the higher the degree of organizational innovation. (2) The higher the degree of organizational centralization, the lower the absorptive capacity of the organization, and then the lower the degree of organizational innovation. (3) The higher the degree of organizational formalization, the slower the organizational decision speed, and then the slower that degree of organizational innovation. (4) The degree of organizational centralization is irrelative to absorptive capacity and decision speed; and therefore organizational innovation speed is not affected.
\end{abstract}

Keywords: Organizational Structure, Absorption Capacity, Decision Speed, Organizational Innovation 


\section{INTRODUCTION}

Innovation is a motive of organizational development. In particular, under a dynamic and complex environment, an organization without continual innovation will very likely become stagnant (Leavy, 1998; Marshall et al., 2009). Therefore, continual innovation is a key to perpetual development. A review of the current literature on organizational innovation indicated the following aspects. (1) Organizational innovation affects organizational performance (Hurley and Hult, 1998; Calantone et al., 2002; Baer and Frese, 2003). (2) A correlation between organizational learning and organizational innovation (Bessant et al., 1996; Baker and Sinkula, 1999; Wang et al., 2010). (3) Organizational structure affects organizational innovation (Miller 1993; Sims, 1996). From the context of the available literature, we found many discussions about organizational innovation, where most studies have used organizational innovation as single interpreting dimension, or interpreted dimension. However, these discussions do not clarify the most important factors that affect or are affected by organizational innovation.

In general, there are many factors affecting organizational innovation. Relevant literature also indicates the significance of organizational learning on organizational innovation. For example, Baker and Sinkula (1999) indicated that organizational learning would promote product innovation; Calantone et al., (2002) indicated that the higher the learning tendency of an organization, the higher its organizational innovation. Hence, organizational learning can affect organizational innovation. What is worthy of mention is that Miller (1993) indicated that rigid organizational structure would generate a phenomenon of organizational inertia, and forms a barrier between knowledge exploration and enterprise reform. This situation also conveys the existence of correlation between organizational structure and organizational innovation. However, past discussions about organizational innovation have focused on the exploration of direction effects of organizational structure on organizational innovation, but have neglected a structural factor affecting organizational learning. Therefore, our first research question of this study is: would organizational structure affect the absorptive capacity of organizational learning and further affect organizational innovation?

There have been studies that have suggested that fast decision speed facilitates organizational innovation (Slevin and Covin, 1995; Jones, Lanctot, and Teegen, 2000; Forbes, 2005). From the viewpoint of organizational structure, it is one of the factors that affects organizational decision speed; i.e. whether organizational structure is centralized or decentralized, or formalized, it would directly affect the speed of 
organizational decisions, and further effect the degree of organizational innovation. Basically, this study considers that the speed of organizational decision lies in the status of organizational structure, which would affect the speed of organizational structure. However, to date, there have been few empirical studies that included the speed of organizational decision-making as an interference variable between organizational structure and organizational innovation. Therefore, our second research question of this study is: would organizational structure affect the speed of organizational decisions, and further affect organizational innovation?

\section{BACKGROUND AND HYPOTHESES}

Past exploration of the factors affecting organizational innovation include consideration of the three levels of "individual", "organization" and "contextual" (Kimberly and Evanisko, 1981; Cooper, 2011). For the organizational level, most studies have focused on organizational structure (such as formalization, centralization and specialization), and held them to have impacts on organizational innovation (e.g., Duhaime and Schwenk, 1985; Fredrickson and Iaquinto, 1989; Slevin and Covin, 1995). Building on past literature, this study herein assumed that it would be oversimplifying the issue by directly attributing organizational structure as the factor affecting organizational innovation. Therefore, this study has indicated that the role of organizational structure in affecting organizational innovation was an antecedent variable, not a descriptive variable of direct effects.

For the issues of study as stated in the previous section, we propose a conceptual model, shown in Figure 1. In this model, organizational structure is conceptualized as formalization and centralization. The model has two considerations: (1) Will organizational structure affect the organizational absorptive capacity and then affect organizational innovation? (2) Will organizational structure affect the speed of organizational decision, then further affect organizational innovation? Based on the conceptual framework, we develop and test the following hypotheses. 


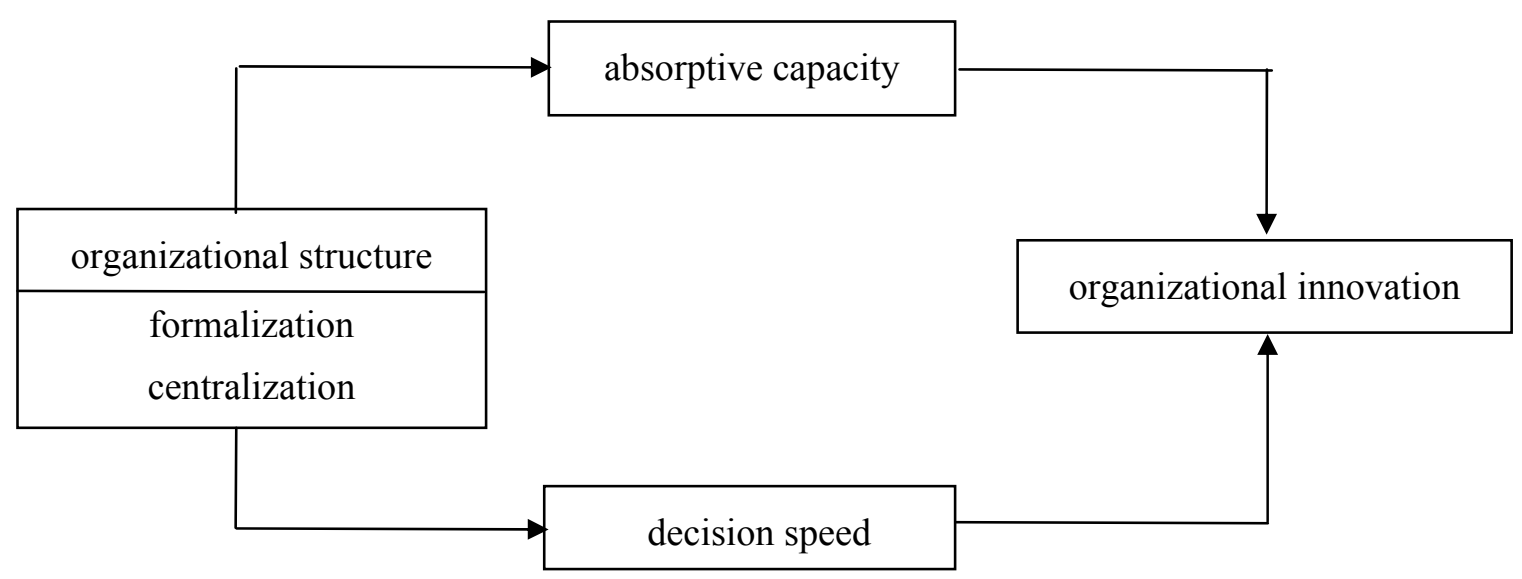

Figure 1 Conceptual model

\section{Organizational structure, absorptive capacity, and organizational innovation}

Organizational structure is divided into mechanistic structure and organic organization. Generally speaking, mechanistic structure has a higher level of formalization and centralization than organic organization, reducing the frequency of communication between the inside and the outside, which is less favorable for organizational innovation (Damanpour, 1991, 1996a, 1996b). Based on the viewpoints of Damanpour, this study advocates that organizational structure will not only merely influence the intensity of organizational innovation directly; but, it may also influence the staff's absorption capacity and organizational decision speed first too, and then subsequently influence organizational innovation.

From the viewpoint of organizational structure, formalization and centralization are always the dimensions discussed by many scholars (Child, 1972; Mintzberg, 1979; Adler, 1999). For example, if a formalized or centralized organizational structure is a restricted operation procedure or authoritarian system, its employees might have insufficient absorptive capacity and lack of the capacity of fast reaction to the change of situation (Hurley and Hult, 1998; Hult et al., 2002; Calantone et al., 2002). Formalization enables a vast organizational memory of best practice, which makes knowledge use more efficient. Nahm et al., (2003) also indicated that formalized structure may result in employees losing their courage of innovation, independence and learning opportunity. In addition, centralized organizational structure is less flexible, but enables promotion of the capacity of information integration and dissemination. It is thus evident that many organizational researchers have argued that the structural characteristics of an organization significantly influence its adoption behavior (Miller, 1993; Nicolini and Meznar, 1995; Sims, 1996). The contention is 
that certain features of organizations themselves either facilitate or encourage adoption of innovation (Fosfuri and Tribo, 2008; Hagemeister and Arturo, 2010).

Discussed in the previous section, even though the relationship between formalization or centralization and adoption of innovation has been found to be positive in some cases, in others the relationship has been negative. However, this study considers that an organization with higher degree of formalization and centralization may make it easy to avoid chaos, inconsistency, and duplicated efforts, especially within a large, complex organization (Adler, 1999). Therefore, this study argues that formalization and centralization of organizational structure would affect staff's absorption capacity, and further affect organizational innovation performance (Chen et al., 2009).

What is the influence in direction among organizational structure, absorption capacity with organizational innovation? This study asserts that a formalization procedure and rules can help organizations filter out incorrect messages and at the same time acquire, assimilate, transfer and apply existing knowledge and capabilities. On the other hand, this study holds that an organization with lower centralization is in a better position to quickly apply and maximize their absorbed knowledge and capabilities for organizational innovation (Azadegan, 2008). As inferred from these ideas, organizational structure would affect the absorptive capacity of an organization and further affect organizational innovation. In order to test the above arguments, this study proposes the following hypotheses:

Hypothesis 1: The higher the degree of organizational formalization, the higher the organizational absorptive capacity, and then the higher the degree of organizational innovation.

Hypothesis 2: The higher the degree of organizational centralization, the lower the organizational absorptive capacity, and then the lower the degree of organizational innovation.

\section{Organizational structure, decision speed, and organizational innovation}

Academic discussion of decision speed emerged initially by Bourgeois and Eisenhardt (1988). There have been few subsequent empirical studies regarding this topic. However, organizational researchers have repeatedly prescribed fast decision as a source of competitive advantage (Jones, 1993), and practitioners claim they increasingly make decisions in less time (Ancona et al., 2001; Kepner-Tregoe, 2001). Basically, decision speed refers to how quickly organizations execute all aspects of 
the decision-making process (Eisenhardt, 1989).

Decision speed denotes how fast businesses adopt strategies in response to external changes. Besides having impacts upon operation of businesses, appropriate decision-making is vital to the maintenance of competitiveness (Lumpkin and Dess, 1996). To be specific, a faster decision speed leads to: (1) Early adoption of products or improvement of business models (Jones et al., 2000); and, (2) Development of new opportunities (Steven and Gumpert, 1985; Zehir and Mehtap, 2008). By digesting literature on organizational structure and organizational speed, it was found that organizations with higher formalization were slower in decision-making (Simon, 1976; Fredrickson and Iaquinto, 1989); members in highly centralized organizations had less motivation to learn, and were less efficient and slower in making decisions (Duhaime and Schwenk, 1985; Slevin and Covin, 1995). It is therefore evident that organization structure is vital to decision speed.

In dynamic environments, firms that make faster decision can exploit opportunities. At the same time, rapid exploitation of such opportunities may give firms first-mover advantages (Makadok, 1998; Tippins and Sohi, 2003). There have been some empirical studies of decision speed, where decision-making in the most successful companies was fast and comprehensive (Wally and Baum, 1994; Baum and Wally, 2003). Other researchers also find that decision-makers may 'keep up with' fast-moving environments as they engage in comprehensive scanning, research, and analysis to yield high performance (Glick et al., 1993; Priem et al., 1995).

On the other side, from the viewpoint of organizational structure, centralization of strategy and formalization of routines are related positively with strategic decision speed (Baum and Wally, 2003). Taken together, these studies underscore the significance of decision speed even while they indicate that its implications for competitive advantage maybe complex and conditional. Specifically, the higher the degree of formalization of an organization, the slower its decision speed (Simon, 1976; Fredrickson and Iaquinto, 1989); the higher the degree of centralization of an organization, the lower the motive and efficiency of its employees, and the lower the decision speed (Duhaime and Schwenk, 1985; Slevin and Covin, 1995). Based on the above arguments, this study argues that the formalization and centralization of organizational structure are relevant to the decision speed of an organization, and further affect the degree of organizational innovation. In order to test the above arguments, this study proposes the following hypotheses: 
Hypothesis 3: The higher the degree of organizational formalization, the slower the decision speed, and then the lower the degree of organizational innovation.

Hypothesis 4: The higher the organizational centralization, the slower the decision speed, and then the lower the degree of organizational innovation.

\section{METHODS}

The operative definition and measurement methods of each variable of this study are described in the following paragraphs.

\section{Operational definition and measurement of organizational structure}

Formalization and centralization are two variables that are often used to measure organizational structure (Jackson and Morgan, 1982; Federickson, 1984; Hodge et al., 2003). This study adopts the definition of Fredrickson (1984), and considers formalization as "the degree of use rules or procedures of an organization directing behaviors of employees" (King and Sabherwal, 1992). In addition, for the concept of centralization, this study adopts the viewpoint of Fredrickson (1984) and King and Sabherwal (1992), which defines it as "the degree of centralization of decision power or activity evaluation". Various measurement items were revised from the questionnaires developed by King and Sabherwal (1992).

\section{Operational definition and measurement of absorptive capacity}

This study divides absorptive capacity into acquisition capacity and identification capacity for the process of acquisition and assimilation of external knowledge. The measurement method for acquisition capacity is mainly based on the definition of Cohen and Levinthal (1990), and is obtained in referencing to the research questionnaire for absorptive capacity of Cohen and Levinthal (1990) and Zahra and George (2002); while identification capacity adopts the measurement for absorptive capacity of Cohen and Levinthal (1990).

\section{Operational definition and measurement of decision speed}

This study adopts the viewpoint of Baum and Wally (2003), which divides measurement indices of organizational decision speed into five items: the speed of making major decisions speedily; the speed of decision of integrating new ideas; the speed of decision of adoption of technology; the speed of decision of launching new products; and, incorporating new technologies into products faster than competitors. 
Make a self-criticism to enter with the scheme.

\section{Operative definition and measurement of organizational innovation}

For the operative definition of organizational innovation, this study follows the viewpoint of Daft (2004) and Damanpour and Schneider (2006), which divides organizational innovation into two aspects: "management innovation" and "technical innovation" (Daft, 1978; Damanpour and Evan, 1984). The scale used here is derived from that developed by Tsai, Huang, and Kao (2001), which defines organizational innovation as: management innovation in company management activities, whether externally imputed or internally generated, as well as technical innovation in respect of product, process and equipment.

The measurement methods for variables of organizational structure formalization or centralization degree, absorptive capacity, decision speed and organizational innovation as stated above adopt the likert scale, which uses a five-point scale. From "strongly disagree" to "strongly agree"; they were given one point to five points, respectively.

\section{Control variables}

In sociology research, as changes of dependant variables are not wholly attributable to independent variables, a control variable was used to decrease the risk of overstated interpretation capacity of independent variable. The control variables of this study adopt five items - organizational age, organizational size, organizational sharing climate, organizational culture, and industrial sector - in order to examine whether organizational structure affects absorptive capacity and decision speed, and further affect organizational innovation (Martins and Terblanche, 2003; Marcati, Guido, and Peluso, 2008).

Among control variables, the measurement of organizational culture in this study was based on the operational definition by Martins and Terblanche (2003) on innovational organizational culture, which used the employees' spirit of adventure, motivation to receive new ideas and pursuit of innovation, motivation to think constantly, vibrant working atmosphere in the organization and aggressiveness in collection of external customer-related information as the items of measurement (Waartz and Van Everdingen, 2005). In addition, the "organization knowledge sharing climate" referred to in this article means the sharing climate in the organization. The operational definition in the regard was adopted from the viewpoints of Davenport (1997) and Davenport and Prusak (1998), which divides the organization-sharing 
climate into "mutualism" and "altruism".

\section{Data collection}

This study used a convenient sampling procedure on the publicly listed companies. For the categories of industries, a total of 260 companies in the manufacturing and service industries were included. The distribution of questionnaires was based on the consideration of total cognitive factors of the organizations and each company was asked to fill out five copies of questionnaires. Respondents were executives at the level of assistant manager or higher, with minimally a 10-year experience in the companies.

The survey period was from February 2008 to July 2008. Convenient sampling was used to decide which companies would be surveyed. Before questionnaires were given, special assistants of the presidents of these companies were contacted for arrangement of survey time. To ensure the collection and effectiveness of the questionnaires, the research team members personally went to those companies to conduct the test, since the companies tested scattered across different regions of Taiwan. The 5-member research team had 8 graduate students assist in the survey process.

RESULTS AND DISCUSSION

\section{Structure analysis of sample}

To assure the timeliness of responses to questionnaires, the survey of the study questionnaires were implemented by the method of site test and site response, after personal visit at each company by members of this study team. 260 companies were visited, and 1,300 copies of questionnaires were distributed. 1251 responses were obtained. Valid questionnaires were comprised of 1182 copies, with a valid response rate of $90.92 \%$. Companies responding to the questionnaires included industries of electrical, food, textile, electronic, finance \& insurance etc, as listed in Table 1. 
Table 1 Frequency distribution of industries

\begin{tabular}{lccc}
\hline \multicolumn{1}{c}{ Industries } & Companies & Percentage & Cumulative percentage \\
\hline Electrical & 7 & 2.7 & 2.7 \\
\hline Food & 10 & 3.8 & 6.5 \\
\hline Textile & 13 & 5.0 & 11.5 \\
\hline Finance \& insurance & 26 & 10.0 & 21.5 \\
\hline Plastic \& chemical & 47 & 18.1 & 39.6 \\
\hline Electronic & 68 & 26.2 & 65.8 \\
\hline Other & 89 & 34.2 & 100.0 \\
\hline Total & 260 & 100.0 & 100.0
\end{tabular}

Note: $1 . \mathrm{N}=260$

2. In empirical process, this study combined Electrical, Food, Textile, Electronic, and Plastic \& Chemical as one "Manufacturing Industry" (a total of 145 companies) and Finance \& insurance and others as one "Service Industry" (a total of 115 companies).

\section{Reliability and validity}

\section{Reliability}

This study adopts a Cronbach $\alpha$ coefficient value for the analysis to measure items under same dimension whether conforming to general reliability test level. As suggested by Nunnally (1978), a value of the Cronbach $\alpha$ coefficient above 0.70 is a high reliability value. At least, the value must reach the minimal standard of 0.50 to meet reliability requirements. If the value was lower than 0.35 , then this scale was not used. After calculation, values of Cronbach's $\alpha$ coefficient of all measurement items of this study were between $0.80-0.95$, which are above standard values, indicating each scale adopted by this study has proper reliability. Reliability values of measurement variables in this study are shown in Table 2 .

Table 2 Reliability values of various measurement variables

\begin{tabular}{ll}
\hline \multicolumn{1}{c}{ Measurement variables } & Reliability (Cronbach's $\alpha$ ) \\
\hline organizational innovation & .858 \\
\hline formalization degree & .813 \\
\hline centralization degree & .922 \\
\hline absorptive capacity & .945 \\
\hline decision speed & .942 \\
\hline Organizational knowledge sharing climate & .872 \\
\hline Innovational organizational culture & .836 \\
\hline
\end{tabular}




\section{Validity}

Variables and questions of organizational structure, absorptive capacity, decision speed, and organizational innovation as explored in this study were based on theories of past relevant literature, and are quoted or revised from scale or measurement items that have been used by other esteemed researchers. In addition, before formal distribution of the questionnaire survey of this study, persons having practical experiences in the industry were requested for a pre-test, and the contents of questionnaires were revised according to their suggestions. After continuous tests and revisions, the measuring tools used in this study should have met validity requirements.

\section{Descriptive statistics of variables}

Descriptive statistics of means, standard deviation and correlation coefficient relating to variables are shown in Table 3. As observed in the Table, all absolute values of coefficients between independent variables are below 0.542 . According to the view of Thomas and Williams (1991), if the correlation coefficient between independent variables is less than 0.65 , there will be no collinearity problems between them, and then affect the results of statistical inferences.

Table 3 Matrix of means, standard deviations, and their correlative coefficients of variables

\begin{tabular}{|c|c|c|c|c|c|c|c|c|c|c|c|}
\hline Research variables & Mean & $\begin{array}{l}\text { Standard } \\
\text { deviation }\end{array}$ & 1 & 2 & 3 & 4 & 5 & 6 & 7 & 8 & 9 \\
\hline $\begin{array}{l}\text { 1. Organizational } \\
\text { age }\end{array}$ & 22.302 & 18.266 & 1 & & & & & & & & \\
\hline $\begin{array}{l}\text { 2. Organizational } \\
\text { size }\end{array}$ & 2.643 & 0.407 & $.391 * * *$ & 1 & & & & & & & \\
\hline $\begin{array}{l}\text { 3. Knowledge } \\
\text { sharing climate }\end{array}$ & 3.997 & 0.393 & .113 & $.144 * *$ & 1 & & & & & & \\
\hline $\begin{array}{l}\text { 4. Organizational } \\
\text { culture }\end{array}$ & 3.470 & 0.556 & -.011 & .028 & $.212 * * *$ & 1 & & & & & \\
\hline $\begin{array}{l}\text { 5. Organizational } \\
\text { innovation }\end{array}$ & 3.505 & 0.450 & -.102 & .043 & $.310 * * *$ & $.530 * * *$ & 1 & & & & \\
\hline $\begin{array}{l}\text { 6. Formalization } \\
\text { degree }\end{array}$ & 3.570 & 0.451 & .015 & $.130 * *$ & $.213 * * *$ & $.509 * * *$ & $.481 * * *$ & 1 & & & \\
\hline $\begin{array}{l}\text { 7. Centralization } \\
\text { degree }\end{array}$ & 4.884 & 0.622 & $.123 * *$ & $.124 * *$ & $.270 * * *$ & $-.175^{* * *}$ & -.110 & -.019 & 1 & & \\
\hline $\begin{array}{l}\text { 8. Organizational } \\
\text { decision speed }\end{array}$ & 3.639 & 0.490 & -.062 & .005 & $.351 * * *$ & $.523 * * *$ & $.512^{* * *}$ & $.542 * * *$ & $-.111^{*}$ & 1 & \\
\hline $\begin{array}{l}\text { 9. Organizational } \\
\text { absorptive capacity }\end{array}$ & 3.475 & 0.491 & -.015 & .108 & $.233 * * *$ & $.435 * * *$ & $.400 * * *$ & $.327 * * *$ & -.080 & $.472 * * *$ & 1 \\
\hline
\end{tabular}




\section{Analysis and discussion}

In the empirical analysis process of this study, based on control over organizational age, organizational size, organizational knowledge sharing climate, organizational culture and industrial sector, the comparative analysis results of the nested model are shown in Table 4. The Table indicates that the GFI (Goodness-of-Fit Index) is 0.96, and NFI (Normed Incremental Fit Index) is 0.97 , both of which are higher than the acceptable level of 0.90. In addition, the SRMR (Standardized Root Mean Square Residual) is 0.036, which is also close to the acceptable level 0.05 . Therefore, the overall GFI in the theoretic model presented in this study has good effect. The hypotheses presented in this study were tested by a nested model analysis as follows:

Tale 4 Analysis and comparison of nested model

\begin{tabular}{|c|c|c|c|c|c|c|}
\hline Model & $\chi^{2}$ & ${ }^{\Delta} \chi^{2}$ & GFI & NFI & CFI & SRMR \\
\hline Theoretical model & 725.21 & $719.15 * * *$ & 0.96 & 0.97 & 0.90 & 0.036 \\
\hline Control variable & 31.83 & $31.61 * * *$ & 0.98 & 0.96 & 0.98 & 0.05 \\
\hline $\begin{array}{l}\text { Model 1 } \\
\text { Formalization degree } \rightarrow \\
\text { organizational innovation }=0\end{array}$ & 95.54 & $92.81 * *$ & 0.96 & 0.92 & 0.95 & 0.05 \\
\hline $\begin{array}{l}\text { Model } 2 \\
\text { Formalization degree } \rightarrow \\
\text { absorptive capacity }=0\end{array}$ & 115.76 & $112.43 * * *$ & 0.96 & 0.90 & 0.94 & 0.04 \\
\hline $\begin{array}{l}\text { Motel } 3 \\
\text { Formalization degree } \rightarrow \text { decision } \\
\text { speed }=0\end{array}$ & 120.54 & $110.75 * * *$ & 0.95 & 0.90 & 0.93 & 0.04 \\
\hline $\begin{array}{l}\text { Model } 4 \\
\text { Absorptive capacity } \rightarrow \\
\text { organizational innovation }=0 \\
\end{array}$ & 252.25 & $113.32 * * *$ & 0.92 & 0.76 & 0.78 & 0.05 \\
\hline $\begin{array}{l}\text { Model } 5 \\
\text { Decision speed } \rightarrow \text { organizational } \\
\text { innovation }=0\end{array}$ & 110.37 & $90.53 * *$ & 0.94 & 0.89 & 0.92 & 0.04 \\
\hline $\begin{array}{l}\text { Model } 6 \\
\text { Centralization degree } \rightarrow \\
\text { organizational innovation }=0 \\
\end{array}$ & 95.73 & 93.25 & 0.97 & 0.91 & 0.96 & 0.04 \\
\hline $\begin{array}{l}\text { Model } 7 \\
\text { Centralization degree } \rightarrow \\
\text { absorptive capacity }=0\end{array}$ & 142.12 & $118.53 * * *$ & 0.88 & 0.89 & 0.90 & 0.13 \\
\hline $\begin{array}{l}\text { Model } 8 \\
\text { Centralization degree } \rightarrow \text { decision } \\
\text { speed }=0\end{array}$ & 110.45 & 129.72 & 0.90 & 0.92 & 0.93 & 0.06 \\
\hline
\end{tabular}

Notes: $1 .{ }^{*} \mathrm{p}<0.1,{ }^{*} * \mathrm{p}<0.05, * * * \mathrm{p}<0.001$

2. GFI (Goodness-of-Fit Index), NFI (Normed Incremental Fit Index), CFI (Comparative Fit Index), SRMR (Standardized Root Mean Square Residual) 


\section{The relationships among organizational formalization degree, absorptive capacity, and organizational innovation}

In Table 4, Model 1 sets the relationship of organizational formalization to organizational innovation to 0 , to explore the direct effect of organizational formalization on organizational innovation. Results indicate that the chi-square value $\left(\chi^{2}\right)$ in Model 1 reaches the significance level, and the goodness-of-fit also shows a significant difference $\left(\triangle \chi^{2}=92.81, \mathrm{p}<0.01\right)$. Model 2 set the relationship of organizational formalization degree to absorptive capacity to 0 , to explore the direct effect of organizational formalization on absorptive capacity. Results indicated that the chi-square value $\left(\chi^{2}\right)$ in Model 2 reached the significance level $\left(\triangle \chi^{2}=112.43\right.$, $\mathrm{P}<0.01$ ). Model 4 set the relationship of absorptive capacity to organizational innovation to 0 , to explore the direct effect of absorptive capacity on organizational innovation. Results find that the chi-square value $\left(\chi^{2}\right)$ in Model 4 reached the significance level, and the goodness-of-fit also shows a significant difference $\left(\triangle \chi^{2}=\right.$ 113.32, $\mathrm{P}<0.01)$.

The above nested analysis results show that organizational formalization would affect absorptive capacity of members of the organization, and further affect the degree of organizational innovation. To further understand their relationship, this study applies path analysis model to test their continual relationship. Results show that the degree of organizational formalization has a positive significant relationship with absorptive capacity, and absorptive capacity has a positive significant relationship with organizational innovation, as indicated in Table 5. Combining empirical results of nested analysis and path analysis, this study finds that the higher the degree of organizational formalization, the higher the absorptive capacity of the organization, and the higher the degree of organizational innovation. These results support Hypothesis 1 presented in this study.

The reasons for above findings might be that: (1) by its establishment of rules and its regulation of system, an organization with a higher degree of formalization probably indicates that the organization has more efficient learning, and stronger absorptive capacity (Hurley and Hult, 1998; Calantone et al., 2002). (2) The adoption of a set of comprehensive standardized procedures and methods would lead to effective acquisition, assimilation, transfer, and application of required knowledge and capacity, and further facilitates the behavior of organizational innovation. What is worthy of mention is that the findings of this study conform to the viewpoint of Zahra and George (2002). 
Table 5 Structural path coefficients under theoretical model

\begin{tabular}{lccc}
\hline \multicolumn{1}{c}{ Relation between variables } & Path coefficient & Standard deviation & t value \\
\hline $\begin{array}{l}\text { Formalization degree } \\
\rightarrow \text { organizational innovation }\end{array}$ & $0.75^{* * *}$ & 0.16 & 4.61 \\
\hline $\begin{array}{l}\text { Formalization degree } \\
\rightarrow \text { absorptive capacity }\end{array}$ & $1.07^{*}$ & 0.66 & 1.64 \\
\hline $\begin{array}{l}\text { Formalization degree } \\
\rightarrow \text { decision speed }\end{array}$ & $-2.27^{* *}$ & 1.04 & -2.19 \\
\hline $\begin{array}{l}\text { Absorptive capacity } \\
\rightarrow \text { organizational innovation }\end{array}$ & $2.53^{* * *}$ & 0.85 & 2.99 \\
\hline $\begin{array}{l}\text { Decision speed } \rightarrow \text { organizational innovation } \\
\begin{array}{l}\text { Centralization degree } \\
\rightarrow \text { organizational innovation }\end{array}\end{array}$ & $0.24^{* * *}$ & 0.09 & 2.46 \\
\hline $\begin{array}{l}\text { Centralization degree } \\
\rightarrow \text { absorptive capacity }\end{array}$ & 0.10 & 0.10 & 0.95 \\
\hline $\begin{array}{l}\text { Centralization degree } \\
\rightarrow \text { decision speed }\end{array}$ & $-1.29^{*}$ & 0.07 & 4.25 \\
\hline
\end{tabular}

Note: 1. Path coefficient is the value of standardization

2. ${ }^{*} \mathrm{p}<0.1 \quad * * \mathrm{p}<0.05 \quad * * * \mathrm{p}<0.001$

\section{The relationships among the organizational centralization degree, absorptive capacity, and organizational innovation}

In Table 4, Model 6 sets the relationship of organizational centralization degree to organizational innovation to 0 , to explore the direct effect of organizational centralization degree on organizational innovation. Results find that the chi-square value $\left(\chi^{2}\right)$ in Model 6 has not reached the significance level, and the goodness-of-fit indicates no significant difference exists $\left(\triangle \chi^{2}=93.25, \mathrm{p}>0.1\right)$. Model 7 set the relationship of organizational centralization degree to absorptive capacity to 0 , to explore the direct effect of organizational centralization degree on absorptive capacity. Results indicate that the chi-square value $\left(\chi^{2}\right)$ in Model 7 has reached a significant level, and the goodness-of-fit has significant difference $\left(\triangle \chi^{2}=118.53, \mathrm{P}<0.1\right)$. Combining Model 4, Model 6 and Model 7, this study observed that the organizational centralization degree has a significant relationship with absorptive capacity, but has no significant direct effect on organizational innovation. This study further adopts a path analysis model to examine any continual relationship, as shown in Table 5. Results show that organizational centralization degree has a significantly negative relationship with absorptive capacity, but absorptive capacity has a positive significant relationship with organizational innovation. These results support Hypothesis 2 presented in this study. 
The reasons for above findings might be that: (1) a centralized organization, in which decision powers are over-centralized in top managers, might decrease the attempt and autonomy of organizational members. (2) In centralized organizations, information is too overloaded and isolated at the top to hinder knowledge utilization (Kohli and Jaworski, 1990). (3) Centralization may inversely relate to market intelligence generation and dissemination. In such case, that organization is less likely to have absorptive capacity, it goes without saying about organizational innovative behaviors.

\section{The relationships among organizational formalization degree, decision speed, and organizational innovation}

In Table 4, Model 3 sets the relationship of organizational formalization degree to decision speed to 0 , to explore the direct effect of organizational formalization degree on decision speed. Results indicate that both chi-square value $\left(\chi^{2}\right)$ and GFI in Model 3 have reached a significant difference $\left(\triangle \chi^{2}=110.75, \mathrm{P}<0.01\right)$. Model 5 sets the relationship of decision speed to organizational innovation to 0 , to explore the direct effect of decision speed on organizational innovation. Results indicate that both chi-square value $\left(\chi^{2}\right)$ and GFI in Model 5 have reached significant difference $\left(\triangle \chi^{2}=\right.$ 90.53, $\mathrm{P}<0.1$ ). These nested analysis results show that organizational formalization degree would affect decision speed of the organization, and further affect the degree of organizational innovation. Similarly, to further understand their relationships, this study adopts a path analysis model to examine their continual relationships. Results show that organizational formalization degree has a negative significant relationship with decision speed, but decision speed has positive significant relationship with organizational innovation, as shown in Table 5. Combining empirical results of nested analysis and path analysis, this study results indicate that the higher the organizational formalization degree, the slower the organizational decision speed, and the lower the organizational innovation degree. This supports Hypothesis 3 presented in this study.

Regarding above findings, it might be that under a dynamic and complex environment, such as dramatic increases in demand or the application of new technological capabilities, formalization refers to the presence of written rules and procedures, thereby making it difficult to acquire and utilize knowledge and then firms that make faster decisions can produce bad decisions. Furthermore, it may be due to the fact that fast decision speeds may improve competitive performance across environments because fast strategic decisions lead to early adoption of successful new products or improved business models that provide innovative advantage (Jones et al., 
2000). Consequently, the higher the degree of organizational formalization, the slower the decision speed, and the lower the degree of organizational innovation.

\section{The relationships among organizational centralization degree, decision speed, and organizational innovation}

In Table 4, Model 8 sets the relationship of organizational centralization to decision speed to 0 , to explore the direct effect of organizational centralization on decision speed. Results indicate that both chi-square value and goodness-of-fit in Model 8 have not reached the significance level $\left(\triangle \chi^{2}=129.72, \mathrm{P}>0.1\right)$. Combining Model 5, Model 6, and Model 8, this study shows that organizational centralization degree would not affect decision speed, and further affect organizational innovation. Similarly, this study further adopts a path analysis model to test their continual relationship. Results show that organizational centralization degree has no significant relationship with decision speed, but decision speed has a positive significant relationship with organizational innovation. These results overturn Hypothesis 4 presented in this study. This might explain that members of a centralized organization, in which decision powers are over-centralized in top managers, lack in autonomy, whether or not decision speed is fast or slow. In such case, that organization is less likely to promote organizational innovation by increasing decision speed.

\section{CONCLUSIONS AND MANAGEMENT IMPLICATIONS}

\section{Conclusions}

This study expands our knowledge of the determinants of organizational innovation beyond the purely absorptive capacity and decision speed factors, and strengthens the theoretical bases of work by explaining the effects with references to organizational structure. In addition, this study is the first to connect organizational structure with organizational innovation that is based on absorptive capacity and decision speed. Indeed, previous studies relating to organizational innovation behaviors unavoidably surrounded the discussions on a single dimension that affects or is affected by organizational innovation behaviors. Few studies have investigated other dimensions to clarify their consequential correlation. Therefore, clarification of relationships in actuality is difficult, and cannot provide insight into complete organizational innovation issues.

Based on the above reasons, this study follows the context of organizational structure analysis, to explore the relationships between organizational structure and organizational innovation from the viewpoints of absorptive capacity and decision 
speed. During the empirical process of this kind of study, after relative variables such as organizational age, organizational size, knowledge sharing climate, organizational culture, and industrial sector etc. are controlled, the results herein indicated two answers: (1) Organizational structure would affect the absorptive capacity of organizational learning, and further affect organizational innovation. Organizational structure would affect organizational decision speed and further affect organizational innovation.

\section{Management implications}

What are the implications of the results for theory and research on organizational innovation? In brief, regardless of absorptive capacity and decision speed, formalization level of organizational structure may be the key factor for influencing organizational innovation. That is to say, the effects of absorptive capacity and decision speed on organizational innovation, formalization of organizational structure plays the key role of antecedent variable. A more detailed elaboration, as below:

\section{Formalized organizational structure can increase the absorptive capacity of organizational learning, and further increase the capacity of organizational innovation}

For an organization with a higher degree of formalization, its operations are built on a set of standardized procedures, so that an organizational member can effectively acquire, assimilate, transfer and apply the required knowledge and capacity, to increase their absorptive capacity of organizational learning. Therefore, an organization with good absorptive capacity can easily acquire, absorb and transfer external information, and thereby facilitate behaviors of organizational innovation (Hurley and Hult, 1998; Zahra and George, 2002). In other words, in order to increase innovation capacity, forming formalized organization structure, creating the climate of organizational learning attempt, and cumulating knowledge of absorptive capacity might be the directions of future efforts.

\section{Formalized organizational structure will restrain organizational decision speed} and further decrease the capacity of organizational innovation

Decision-making is often built on a sudden process. In an organization with a higher degree of formalization, first chances are usually lost due to the restriction of standardized operation procedure. Therefore, the findings of this study imply that if an organization aims to increase its innovation behavior, proper decrease in degree of organizational formalization so as to increase decision speed, might be helpful to 
organizational innovation behavior.

\section{Limitation of the study}

This study adopted a convenient sampling procedure on the publicly listed companies. A heterogeneity did exist among the companies in each industry for the samples being studied. Although industry factors were regarded as control variables during the empirical process in this article, they could cause small interference with the net relationship of the independent variables (absorption capacity and decision speed) and antecedent variable (organizational structure) with organizational innovation. This is a limitation of this study. In future research, we will improve sampling difficulties to strengthen the relationship between independent variables and dependent variables.

\section{REFERENCES}

Adler, P. S. (1999). Building better bureaucracy. The Academy of Management Executive, 13(4), 36-49.

Ancona, D. G., Okhuysen, G. A., and Perlow, L. A. (2001). Taking time to integrate temporal research. Academy of Management Review, 26(4), 512-529.

Azadegan, A. (2008). Supplier innovativeness and manufacturer performance: an organizational learning perspective. Unpublished dissertation, Arizona State University, USA.

Baer, M., and Frese, M. (2003). Innovation is not enough: climates for initiative and psychological safety, process innovations, and Firm Performance. Journal of Organizational Behavior, 24(1), 45-68.

Baker, W. E., and Sinkula, J. M. (1999). The synergistic effect of market orientation and learning orientation on organizational performance. Journal of the Academy of Marketing Science, 27(4), 411-427.

Baum, J. R., and Wally, S. (2003). Strategic decision speed and firm performance. Strategic Management Journal, 24(11), 1107-1129.

Bessant, J., Caffyn, J. J., and Gilbert, J. (1996). Learning to manage innovation. Technology Analysis and Strategic Management, 8(1), 59-70.

Bourgeois, L. J., and Eisenhardt, K. (1988). Strategic decision processes in high velocity environments: four cases in the microcomputer industry. Management Science, 34(7), 816-835. 
Calantone, R. J., Cavusgil, S. T., and Zhao, Y. (2002). Learning orientation, firm innovation capability and firm performance. Industrial Marketing Management, 31(6), 515-524.

Chen, Y. S., Lin, M. J., and Chang, C. H. (2009). The positive effects of relationship learning and absorptive capacity on innovation performance and competitive advantage in industrial markets. Industrial Marketing Management, 38(2), 152-161.

Child, J. (1972). Organization structure and strategies of control-a replication of the aston study. Administrative Science Quarterly, 17(2), 163-177.

Cohen, W. M., and Levinthal, D. A. (1990). Absorptive capacity: a new perspective on learning and innovation. Administrative Science Quarterly, 35(1), 128-152.

Cooper, J. J., Jr. (2011). The integral role of organizational characteristics and their impact on lean implementation success. Unpublished dissertation, Southern Illinois University, Carbondale, USA.

Daft, R. L. (1978). A dual-core model of organizational innovation. Academy of Management Journal, 21(2), 193-210.

Daft, R. L. (2004). Organization Theory and Design (8th. Ed.). Ohio: South-Western College Publishing.

Damanpour, F., and Evan, W. M. (1984). Organizational innovation and performance: the problem of organizational lag. Administrative Science Quarterly, 29(3), 392-409.

Damanpour, F. (1991). Organizational innovation: a meta-analysis of effects of determinants and moderators. Academy of Management Journal, 34(3), 555-590.

Damanpour, F. (1996a). Organizational complexity and innovation: developing and testing multiple contingency models. Management Science, 42(5), 693-716.

Damanpour, F. (1996b). Bureaucracy and innovation revisited: effects of contingency factors, industrial sectors, and innovation characteristics. Journal of High Technology Management Research, 7(2), 149-173.

Damanpour, F., Schneider, M. (2006). Phases of the adoption of innovation in organizations: effects of environment, organization and top managers. British Journal of Management, 17(3), 215-236.

Davenport, T. H., and Prusak, L. (1998). Working Knowledge: How Organizations Manage What They Know. Boston: Harvard Business School Press.

Davenport, H. T. (1997). Ten principles of knowledge management and four case studies. Knowledge and Process Management, 4(3), 187-208. 
Duhaime, I. M., and Schwenk, C. R. (1985). Conjectures on cognitive simplification in acquisition and divestment decision making. Academy of Management Review, 10(2), 287-295.

Eisenhardt, K. (1989). Making fast strategic decisions in high-velocity environments. Academy of Management Journal, 32(3), 543-576.

Fredrickson, J. W., and Iaquinto, A. L. (1989). Inertia and creeping rationality in strategic decision processes. Academy of Management Journal, 32(3), 516-542.

Fredrickson, J. W. (1984). The effect of structure on the strategic decision process. Academy of Management Proceedings, 44(1), 12-16.

Forbes, D. P. (2005). Managerial determinants of decision speed in new ventures. Strategic Management Journal, 26(4), 355-366.

Fosfuri, A. and Tribo, J. A. (2008). Exploring the antecedents of potential absorptive capacity and its impact on innovation performance. Omega, 36(3), 173-187.

Glick, W. H., Miller, C. C., and Huber, G. P. (1993). The impact of upper echelon diversity on organizational performance. In Huber, G. P., and Glick, W. H. (Eds.), Organizational change and Redesign: Ideas and Insights for Improving Performance (pp. 176-214). New York: Oxford University Press.

Hagemeister, M., and Arturo, R. C. (2010). Organizational capacity to absorb external R\&D: industrial differences in assessing intellectual capital drivers. Knowledge Management Research and Practice, 8(2), 102-111.

Hodge, B. J., Anthony, W. P., and Gales, L. M. (2003). Organization Theory: A Strategic Approach (6th. Ed.). New Jersey: Prentice Hall Inc.

Hult, G. T. M., Ferrell, O. C., and Hurley, R. F. (2002). Global organizational learning effects on cycle time performance. Journal of Business Research, 55(5), 377-387.

Hurley, R. F., and Hult, G. T. M. (1998). Innovation, market orientation, and organizational learning: an integration and empirical examination. Journal of Marketing, 62(3), 42-54.

Jackson, J. H., and Morgan, C. O. (1982). Organization Theory: A Macro Perspective for Management. Englewood Cliffs, NJ: Prentice-Hall.

Jones, J. W. (1993). High Speed Management: Time-Based Strategies for Managers and Organizations. San Francisco, CA: Jossey-Bass.

Jones, G. K., Lanctot, A., and Teegen, H. J. (2000). Determinants and performance impacts of external technology acquisition. Journal of Business Venturing, 16(3), 255-283.

Kepner-Tregoe, G. (2001, May 14). Hurry up and decide. Business Week, Iss.3732, 16. 
Kimberly, J. R. and Evanisko, M. J. (1981). Organizational innovation: the influence of individual, organizational, and contextual factors on hospital adoption of technological and administrative innovations. Academy of Management Journal, 24(4), 689-713.

King, W. R., and Sabherwal, R. (1992). The factors affecting strategic information systems applications. Information and Management, 23(4), 217-235.

Kohli, A. K., and Jaworski, B. J. (1990). Market orientation: the construct, research propositions, and managerial implications. Journal of Marketing, 54(2), 1-18.

Leavy, B. (1998). The concept of learning in the strategy field: review and outlook. Management Learning, 29(4), 447-466.

Lumpkin, G. T., and Dess, G. G. (1996). Clarifying the entrepreneurial orientation constructs and linking it to performance. Academy of Management Review, 21(1), 135-172.

Makadok, R. (1998). Can first-mover and early-mover advantages be sustained in an industry with low barriers to entry/imitation? Strategic Management Journal, 19(7), 683-696.

Marcati, A., Guido, G., and Peluso, A. M. (2008). The Role of SME Entrepreneurs' Innovativeness and Personality in the Adoption of Innovations. Research Policy, 37(9), 1579-1590.

Marshall, J., Smith, S., and Buxton, S. (2009). Learning organizations and organizational learning: what have we learned? Management Services, 53(2), 36-44.

Martins, E. C., and Terblanche, F. (2003). Building organizational culture that stimulates creativity and innovation. European Journal of Innovation Management, 6(1), 64-74.

Miller, D. (1993). The architecture of simplicity. Academy of Management Journal, 18(1), 116-138.

Mintzberg, H. (1979). The Structuring of Organizations. Englewood Cliff, NJ: Prentice-Hall.

Nahm, A. Y., Vonderembse, M. A., and Koufteros, X. A. (2003). The impact of organizational structure on time-based manufacturing and plant performance. Journal of Operations Management, 21(3), 281-306.

Nicolini, D. and Meznar, M. B. (1995). The social construction of organizational learning: conceptual and practical issues in the field. Human Relations, 48(7), 727-746.

Nunnally, J. C. (1978). Psychometric Theory. New York: McGraw-Hill. 
Priem, R. L., Rasheed, A. M. A., and Kotulic, A. G. (1995). Rationality in strategic decision processes, environmental dynamism and firm performance. Journal of Management, 21(5), 913-929.

Sims, H. A. (1996). Business without Bosses. New York: Wiley.

Simon, H. A. (1976). Administrative Behavior (3rd. Ed.). New York: Free Press.

Slevin, D. P., and Covin, J. G. (1995). Entrepreneurship as firm behavior. In Katz, J. A., and Brockhaus, Sr R. H. (Eds.), Advances in Entrepreneurship, Firm Emergence, and Growth (pp. 175-224). Greenwich, CT: JAI Press.

Steven, H., and Gumpert, D. (1985). The heart of entrepreneurship. Harvard Business Review, 63(2), 85-94.

Thomas, A. S., and Williams, G. R. (1991). A strategy to provide retirement benefits for international transferees in a global company. Benefits and Compensation International, 21(3), 2-7.

Tippins, M. J., and Sohi, R. S. (2003). IT competency and firm performance: is organizational learning a missing link? Strategic Management Journal, 24(8), 745-761.

Tsai, C. T., Huang, K. L., and Kao, C. F. (2001). The relationships among organizational factors, creativity of organizational members and organizational innovation. Management Review, 18(4), 527-566.

Wang, Yu-Lin, Wang, Yau-De, and Horng, Ruey-Yun. (2010). Learning and innovation in small and medium enterprises. Industrial Management + Data Systems, 110(2), 175-192.

Waartz, E. and Van Everdingen, Y. (2005). The influence of national culture on the adoption status of innovation: an empirical study of firms across the Europe. European Management Journal, 23(6), 601-610.

Wally, S. and Baum, J. (1994). Personal and structural determinants of the pace of strategic decision making. Academy of Management Journal, 37(4), 932-956.

Zahra, S. A., and George, G. (2002). Absorptive capacity: a review, re-conceptualization, and extension. The Academy of Management Review, 27(2), 185-203.

Zehir, C., and Mehtap, O. (2008). A field research on the relationship between strategic decision-making speed and innovation performance in the case of Turkish large-scale firms. Management Decision, 46(5), 709-724. 


\section{APPENDIX: MEASUREMENT SCALE ITEMS}

\section{Organizational innovation}

The superiors use new management methods to effectively motivate subordinates and boost morale.

Our firm changes service items and methods based on the customers' needs.

The employees often come up with many ideas to improve production processes or operation procedures.

Our firm constantly introduces new techniques to improve production processes or operation procedures.

Our firm constantly develops some new products are services acceptable in the market.

\section{Level of formalization}

Our firm has procedures to follow in all circumstances.

Rules or procedures exist mostly in a civilized way.

Employees are constantly evaluated for compliance with rules.

Those who break the rules are punished.

\section{Level of centralization}

Decisions over the budgets are controlled by senior executives

Decisions over introduction of new products are controlled by senior executives

Decisions over new market entrance are controlled by senior executives

Decisions over pricing of new product lines are controlled by senior executives

Decisions over deployment of human resources are controlled by senior executives

\section{Decision Speed}

In making decisions, our firm's speed is very fast.

Our firm is able to integrate ideas and make decisions speedily.

In the implementation of decision-making, our speed is very fast.

Our firm launches new products faster than competitors.

Our firm incorporates new technologies into products faster than competitors.

\section{Absorption capability}

The employees have more access to knowledge than those of the competitors.

The employees have a higher ability to search knowledge than those of the competitors.

The employees have a higher ability to identify value of external knowledge to our firm than those of the competitors.

The employees have a higher ability to predict the future development of the core knowledge of our firm than those of the competitors. 
The employees' knowledge comes more from transfer or learning from outside as compared to those of the competitors.

The employees have a higher ability to obtain external knowledge for operation than those of the competitors.

\section{Organization knowledge sharing climate}

Employees are usually willing to share their knowledge and experience with others. An employee tries his best to provide opinions in discussions with others.

An employee tries his best to answer his colleagues' questions.

An employee is much willing to demonstrate to others for things difficult to explain. Employees are willing to give colleagues with inadequate experiences a chance to try.

Employees will provide others with the necessary data and documents when they are in need.

An employee seeks other help when he or she is unable to solve problems for others.

\section{Innovational organizational culture}

Most of the employees are adventuristic and aggressive.

Our firm encourages employees to receive new concepts and seek innovation.

Our firm constantly encourages employees to think.

The workplace is filled with vibrant atmosphere.

Our firm actively collects customer or product related information from outside. 